\title{
O RECONHECIMENTO DO DIREITO HUMANO À ÁGUA A PARTIR DO CASO BRASILEIRO $^{1}$
}

RECOGNITION OF THE HUMAN RIGHT TO WATER FROM THE BRAZILIAN CASE

Guilherme Correa BIANCHINI²

Manoel Ilson Codeiro ROCHA ${ }^{3}$

ISSUE DOI: 10.21207/2675-0104.2019.969

\begin{abstract}
RESUMO
Recentemente o debate sobre o direito humano à água se intensificou, tendo em vista que a Assembleia Geral da Organização das Nações Unidas, por meio da Resolução 64/292, no ano de 2010, reconheceu o acesso à água e saneamento como um direito humano fundamental. Desta forma, se faz necessária a inserção deste debate no âmbito do direito brasileiro considerando-se que a Constituição Federal de 1988, ao guiar todo o ordenamento jurídico do país, coloca os direitos humanos fundamentais em uma posição de prioridade e possibilita a adoção de tratados internacionais de direitos humanos como Emendas Constitucionais. Além disto, deve-se considerar as menções ao direito humano à água, ainda que inserido dentro de outros direitos, em convenções e tratados internacionais elaborados a partir da metade do século XX. Desta forma, este trabalho buscou compreender a natureza da água como um bem fundamental à condição humana, contribuir para a análise da concretização de uma abordagem acerca do surgimento da fundamentalidade de um direito na ordem internacional, bem como a compreensão dos impactos imediatos e mediatos deste surgimento na ordem jurídica brasileira. A
\end{abstract}

${ }^{1} \mathrm{O}$ presente artigo sintetiza a monografia de conclusão da pesquisa, realizada para o Programa Interno de Bolsas de Iniciação Científica (PIBIC 2018-2019) da Faculdade de Direito de Franca (FDF), Franca/SP.

${ }^{2}$ Discente da Faculdade de Direito de Franca (FDF), Franca/SP. Bolsista do Programa Interno de Bolsas de Iniciação Científica (PIBIC 2018-2019).

3 Graduado em Direito pela Universidade Estadual Paulista-UNESP (1996). Mestre em Direito Público pela Universidade Estadual Paulista - UNESP (2000). Doutor em Direito Administrativo pela Universidade de Lisboa - UL (2015). Atualmente é professor de Direito Internacional na Faculdade de Direito de Franca. 
pesquisa foi de natureza qualitativa e foi realizada por uma revisão bibliográfica, normativa e documental.

Palavras-chave: Direito Humano à Água. Constituição Federal. Tratados Internacionais.

\begin{abstract}
Recently, the debate on the human right to water has intensified, as the United Nations General Assembly, through the Resolution 64/292, in 2010, recognized access to water and sanitation as a fundamental human right. Thus, it is necessary to insert this debate within the scope of Brazilian Law considering that the Federal Constitution of 1988, in guiding the entire legal system of the country, places fundamental human rights in a priority position and enable the adoption of international treaties on human rights as Constitutional Amendments. In addition, mention must be made of the human right to water, even if included within other rights, in international conventions and treaties draft from the mid-twentieth century. Thus, this work sought to understand the nature of water as a fundamental good to the human condition, contribute to the analysis of the implementation of the approach about the emergence of the fundamentality of a right in the international order, as well as the understanding of the immediate and mediate impacts of this emergence of rights in the brazilian legal order. The research was qualitative in nature and was conduced by a bibliographical, normative and documentary review.
\end{abstract}

Keywords: Human Right to Water. Federal Constitution. International Treaties.

\title{
INTRODUÇÃO
}

Dentre os recursos mais essenciais e estratégicos para a humanidade está a água, sem a qual não há condições básicas de sobrevida humana e a manutenção dos ecossistemas. Baixos índices de desenvolvimento humano estão diretamente relacionais com a escassez ou a baixa qualidade da água, que dificultam o acesso e o atendimento das mais básicas necessidades humanas, como a produção de alimentos, a dessedentação e a higiene. Desta forma, é evidente a necessidade de iniciativa política para o desenvolvimento deum tratamento superior a este recurso, bem como seu resguardo e preservação, tendo em vista sua essencialidade.

A intensificação do desenvolvimento a partir da rápida industrialização que se teve nos anos 1960 desencadeou o crescimento desordenado dos aglomerados urbanos e dos modos de produção a partir de uma perspectiva puramente economicista que colocou os Estados e a comunidade internacional perante a evidência de que os recursos naturais não são inesgotáveis. Esta dinâmica, ainda em desenvolvimento, passou a impor novos compromissos aos Estados no que diz respeito a elaboração de políticas públicas que impactam diretamente no bem-estar dos cidadãos. 
Neste sentido, destacam-se muitas iniciativas para a gestão e preservação dos recursos ambientais a partir da inserção da água em um espaço significativo na agenda internacional, tendo em vista o grande número de pessoas que ainda não tem acesso à água potável no mundo. Os anos entre 1980 e 1990 foram considerados pela Organização das Nações Unidas (ONU) como a Década da Água e do Saneamento e, em 2002, a ONU, por meio de seu Comentário Geral n ${ }^{\circ} 15$ do seu Comitê dos Direitos Econômicos, Sociais e Culturais, constatou que o direito à água é um requisito para o alcance e efetivação dos demais direitos humanos, tendo como argumento de que a água é elemento essencial para uma vida digna.

Assim, no âmbito internacional, consolidou-se um debate acerca da água como um direito humano fundamental e, no ano de 2010, o acesso à água potável e o saneamento foi formalmente reconhecido como um direito humano pela Resolução 62/292 da Assembleia Geral da Organização das Nações Unidas. Muitos outros documentos internacionais já reconhecem a água como um direito, mesmo que implicitamente, dentre eles a Convenção de Genebra, de 1949, a Convenção sobre a Eliminação de Todas as formas de Discriminação Contra a Mulher, de 1979 e a Convenção sobre os Direitos da Criança, de 1989, o que insere a água no âmbito do direito internacional dos direitos humanos.

No Brasil, se tem a Constituição Federal de 1988 como o marco do reconhecimento dos direitos humanos no ordenamento jurídico do país que, além de oferecer um extenso rol de direitos e garantias fundamentais, oferece também a possibilidade de extensão deste, tendo em vista a possibilidade de absorção de normas de direitos humanos oriundas de tratadas e convenções internacionais.

No que diz respeito à água, no terceiro capítulo desta pesquisa, serão abordados alguns aspectos da legislação vigente para a gestão desse recurso. A Constituição Federal define a água como um bem de domínio público e define questões de dominialidade entre os entes federados e algumas leis esparsas estabelecem as regras que incidem na gestão da água. Esta gestão reconhece a água como um elemento essencial, mas a reconhece como um bem dotado de valor econômico, o que insere a água na economia de mercado, o que deixa este bem suscetível às regras da oferta e da procura, gerando dificuldades às pessoas mais necessitadas.

Desta forma, é proposta uma reflexão sobre a possibilidade do reconhecimento e da efetivação do direito humano à água no Brasil, tendo em vista os pressupostos jurídicos existentes a partir da Constituição 
Federal de 1988, da legislação vigente e dos tratados e convenções internacionais.

A importância do reconhecimento do direito humano à água é inegável devido à sua indispensabilidade para a vida humana, tanto para o suprimento das necessidades básicas, como o consumo direto de água e o preparo e produção de alimentos, tanto para o próprio desenvolvimento de uma nação. Neste sentido, José Galizia Tundisi, citando Bhatia \& Bhatia, destaca a importância da água para o desenvolvimento humano:

\begin{abstract}
Economias regionais e nacionais dependem da disponibilidade adequada de água para geração de energia, abastecimento público, irrigação e produção de alimentos (agricultura, aquicultura e pesca, por exemplo). Melhorar a gestão dos recursos hídricos [...] é uma das formas mais relevantes de desenvolvimento econômico e social, pois melhora a qualidade de vida, promove geração de empregos e renda e amplia a capacidade de abastecimento de água para usos múltiplos e estímulo à economia ${ }^{4}$.
\end{abstract}

Portanto, é notável que o direito à água tem grande potencial para ser considerado como direito fundamental pelo ordenamento jurídico brasileiro, não só pela essencialidade deste elemento para a vida humana, mas também pela existência de uma nova tendência internacional nos direitos humanos que tem resultado em resoluções e tratados que versam sobre o tema. Neste âmbito, também cabe ressaltar leis, tanto federais quando estaduais, que versam a respeito da questão da água e sua substancialidade, mesmo que estas necessitem de algumas reformas para melhor abordarem a água como um direito humano. Isto posto, é inegável possibilidade de enquadrar o direito humano à água na Constituição Federal de 1988.

Esta pesquisa teve como objetivo geral compreender a natureza da água como um bem fundamental à condição humana, caracterizando-se como um direito e com implicações em outras relações jurídicas decorrentes do uso da água, como, por exemplo, a água como um bem de valor - e de domínio - e a água como um componente ecológico fundamental para o equilíbrio do planeta e da vida em geral, não apenas para o bem-estar dos indivíduos.

Como objetivos específicos deste estudo, se tem a contribuição para análise da concretização de uma abordagem acerca do surgimento da fundamentalidade de um direito na ordem jurídica internacional, bem como

\footnotetext{
${ }^{4}$ BHATIA \& BHATIA apud TUNDISI, J. G. Recursos Hídricos no Futuro: Problemas e Soluções. Estudos Avançados, v. 22, n. 63. São Paulo, 2008.
} 
a compreensão dos impactos imediatos e mediatos deste surgimento na ordem jurídica interna brasileira.

A referida pesquisa foi de natureza qualitativa e teve caráter bibliográfico devido ao seu conteúdo doutrinário e à análise normativa e documental. Para que os objetivos desta pesquisa sejam alcançados um estudo doutrinário sobre Direitos Humanos e Direito Constitucional será realizado, bem como a literatura crítica da área, como artigos científicos publicados em periódicos levantados em bancos de dados como a plataforma Scielo. Desta forma pretendeu-se compreender desde o surgimento da fundamentalidade de um determinado direito na ordem internacional até a sua inclusão no ordenamento jurídico interno.

O caráter normativo e documental desta pesquisa se deu devido ao uso de textos de leis, como a Lei 9.433/97 e a Constituição Federal de 1988, e documentos emitidos por organizações internacionais, como as Resoluções da Organização das Nações Unidas, e por agências multilaterais, como os documentos gerenciais do Banco Mundial. Tais documentos serão levantados por meio dos bancos de dados online fornecidos pelas próprias instituições, nos quais serão inseridas palavraschave de pesquisa como: human rights, human right to water, world bank water, United nations water.

\section{OS DIREITOS HUMANOS NA ORDEM JURÍDICA INTERNACIONAL}

Em meados do século XX, com o fim da Segunda Guerra Mundial, em resposta as atrocidades cometidas pelo Nazismo e seu regime do terror ao qual pode ser atribuído grandes violações de direitos humanos, surgiu uma necessidade generalizada de que uma forma de manutenção da paz. Com isto, "a comunidade internacional passou a reconhecer que a proteção dos direitos humanos constitui questão de legítimo interesse e preocupação internacional" ". Este movimento do Direito Internacional dos Direitos Humanos, como afirma Richard B. Bilder, se baseia na concepção de que toda nação deve respeitar tais direitos e que a comunidade

\footnotetext{
${ }^{5}$ PIOVESAN, Flávia. Direitos humanos e o direito constitucional internacional. São Paulo: Max Limonad, 1996. p. 5.
} 
internacional tem a responsabilidade de protestar perante $\mathrm{o}$ não cumprimento destas normas internacionais ${ }^{6}$.

Esta abordagem abrangente proporcionada pela ótica dos direitos humanos é algo relativamente recente, tendo em vista que, de acordo com alguns autores, a internacionalização atual dos direitos humanos ocorreu apenas no período subsequente à Segunda Guerra Mundial, e à esta internacionalização precedem alguns marcos importantes para a atual construção e sistemática dos direitos humanos a serem destacados.

Tradicionalmente, nos dizeres de Thomas Buergenthal et al., o Direito Internacional era definido como a lei que imperava sobre as relações entre os Estados-nações, exclusivamente, demonstrando que apenas estes eram sujeitos de direitos e obrigações na ordem internacional ${ }^{7}$. Esta ideia imperava legitimada pelo argumento de que "a maneira que o Estado tratava os seus próprios cidadãos não era regulada pelo Direito Internacional pois isto não afetaria sua relação com outros Estados" ". Porém, ainda segundo os mesmos autores, existiram algumas exceções como as intervenções humanitárias, alguns tratados e organizações, como a Organização Internacional do Trabalho, e a Liga das Nações, que contribuíram para a internacionalização dos direitos humanos a partir do fim da Segunda Guerra Mundial.

Desta forma, como destaca Flavia Piovesan, o Direito Humanitário foi a primeira manifestação internacional como um Direito Internacional da Guerra, limitando a liberdade dos Estados em hipótese de conflito armado, exigindo a observância de alguns direitos fundamentais tanto em relação a militares quanto em relação as populações civis ${ }^{9}$. Neste sentido, também cabe destaque à Liga das Nações que, reforçando a ideia de limitação da ação dos Estados em situação de guerra, em 1919, na Europa desgastada pela Primeira Guerra Mundial, passou a "supervisionar o desarmamento, arbitrar as disputas entre as nações e garantir os direitos para as minorias nacionais, mulheres e crianças" ${ }^{10}$. Esta se mostrou

\footnotetext{
${ }^{6}$ BILDER, Richard B. An overview of international human rights law. In: HANNUM, Hurst, Ed. Guide to international human rights practice. $2^{\mathrm{a}}$ ed. Philadelphia, University of Pennsylvania Press. 1992.

${ }^{7}$ BUERGENTHAL, Thomas; SHELTON, Dinah; STEWART, David P. International Human Rights in a Nutshel. George Washington University Law School Legal Studies Paper, 4 ed, 2009. p. 2.

${ }^{8}$ Ibidem.

${ }^{9}$ PIOVESAN, Flávia. op. cit., p. 111-112.

${ }^{10}$ HUNT, Lynn. A invenção dos direitos humanos. ${ }^{\text {a }}$ ed. São Paulo: Companhia das Letras, 2009. p. 202.
} 
impotente e veio a fracassar com a ascensão do fascismo italiano e o nazismo alemão.

Destacados tais precedentes, findo o regime nazista na Alemanha e, portanto, a Segunda Guerra Mundial, foi criada, em 1945, a Organização das Nações Unidas (ONU) como um ator que conjugou a comunidade internacional para impedir que massacres desumanos das grandes guerras acontecessem novamente. Seu primeiro instrumento para o resguardo dos direitos humanos foi a Declaração Universal de Direitos Humanos (DUDH), aprovada por quarenta e oito Estados, com oito abstenções, em dezembro de $1948^{11}$, legitimando sua força, já que:

A inexistência de qualquer questionamento ou reserva feita pelos Estados aos princípios da Declaração e a inexistência de qualquer voto contrário às suas disposições, conferem à Declaração Universal o significado de um código e plataforma comum de ação. A Declaração consolida a afirmação de uma ética universal, ao consagrar um consenso sobre valores de cunho universal, a serem seguidos pelos Estados ${ }^{12}$.

Sobre a DUDH, a ONU explica:

\begin{abstract}
A Declaração Universal dos Direitos Humanos (DUDH) é um documento marco na história dos direitos humanos. Elaborada por representantes de diferentes origens jurídicas e culturais de todas as regiões do mundo, a Declaração foi proclamada pela Assembleia Geral das Nações Unidas em Paris, em 10 de dezembro de 1948, por meio da Resolução 217 A (III) da Assembleia Geral como uma norma comum a ser alcançada por todos os povos e nações. Ela estabelece, pela primeira vez, a proteção universal dos direitos humanos ${ }^{13}$.
\end{abstract}

Assim, a universalidade desta declaração se caracteriza pois, pela primeira vez na história da humanidade, esta não é baseada apenas em princípios, "mas de fato, na medida em que o consenso sobre a sua validade e sua capacidade para reger os destinos da comunidade futura e de todos os homens foi explicitamente declarado"14. Este princípio é expresso pela Declaração logo em seu preâmbulo e em seu primeiro artigo, onde é

\footnotetext{
${ }^{11}$ PIOVESAN, Flávia. Temas de direitos humanos / Flávia Piovesan - 5. ed. - São Paulo: Saraiva, 2012. p. 142.

12 Ibidem.

13 NAÇÕES UNIDAS. A Declaração Universal dos Direitos Humanos. Disponível em: <https://nacoesunidas.org/direitoshumanos/declaracao/>. Acesso em: 18 jan. 2019.

${ }^{14}$ BOBBIO, Norberto. A Era dos Direitos. Nova edição, Tradução: Carlos Nelson Coutinho. Rio de Janeiro: Elsevier, 2004. p. 18.
} 
afirmado que: "todos os seres humanos nascem livres e iguais em dignidade e direitos. São dotados de razão e consciência e devem agir em relação uns aos outros com espírito de fraternidade" 15 , tornando-se "uma consequência que abalou a doutrina e a prática do direito internacional: todo indivíduo foi elevado a sujeito potencial da comunidade internacional, cujos sujeitos até agora considerados eram, eminentemente, os Estados soberanos ${ }^{16 "}$ - como previamente mencionado.

A DUDH, de 1948, ainda é o documento que consolida a concepção contemporânea dos Direitos Humanos, conjugando os valores de liberdade e igualdade, e constituindo-os como um complexo interdependentes, como fixado pela Resolução 32/130 da ONU, a saber: "todos os direitos humanos, qualquer que seja o tipo a que pertencem, se inter-relacionam necessariamente entre si, e são indivisíveis e interdependentes $^{17}$,

\section{OS DIREITOS HUMANOS NO ORDENAMENTO JURÍDICO BRASILEIRO}

O período de intensificação das abordagens sobre direitos humanos no Brasil teve início com a redemocratização do país na década de 1980. Flávia Piovesan destaca que a partir de 1985 o Estado brasileiro passou a ratificar grandes e relevantes tratados internacionais de direitos humanos, sendo o marco inicial deste processo de incorporação de pactos e tratados a ratificação da Convenção contra a Tortura e Outros Tratamento Cruéis, Desumanos ou Degradantes, em 1989, sob a égide da Constituição Federal de $1988^{18}$.

Neste contexto, com estas ações, o Brasil havia cumprido quase todas as formalidades externas para a sua adesão ao sistema internacional de proteção aos direitos humanos e, internamente, a ampla garantia de direitos fixada pela Constituição Federal de 1988 "asse guram a disposição do Estado democrático brasileiro de conformar-se plenamente às

\footnotetext{
15 NAÇÕES UNIDAS. A Declaração Universal dos Direitos Humanos. Disponível em: <https://nacoesunidas.org/direitoshumanos/declaracao/>. Acesso em: 18 jan. 2019.

${ }^{16}$ BOBBIO, Noberto. op. cit. p. 47.

${ }^{17}$ PIOVESAN, Flávia. Temas de direitos humanos / Flávia Piovesan - 5. ed. - São Paulo: Saraiva, 2012. p. 148.

${ }^{18}$ Ibidem, p. 159-168.
} 
obrigações internacionais por ele contraídas"19. Além das inovações introduzidas pela nova Constituição, que possibilitaram a ratificação de um amplo rol de tratados, Flavia Piovesan também destaca "a necessidade do Estado brasileiro de reorganizar a sua agenda internacional, de modo condizente com as transformações internas decorrentes do processo de democratização" ${ }^{20}$.

Estes esforços e mudanças foram essenciais para a construção de uma boa imagem internacional para o país, como um Estado garantidor dos direitos humanos e uma inserção no contexto da globalização. Assim, é evidente a relação da institucionalização dos direitos humanos no Brasil a partir de 1988, com a nova Constituição Federal, que permitiu a ratificação dos tratados internacionais de direitos humanos tornando estes equivalentes a emendas constitucionais após a aprovação no Congresso Nacional, conforme expresso no Artigo $5^{\circ}$, parágrafo $3^{\circ}$.

Logo em seu artigo $1^{\circ}$, a Constituição Federal de 1988, define a dignidade humana como seu princípio fundamental, impondo-se "como núcleo básico e informador do ordenamento jurídico brasileiro, como critério e parâmetro de valoração a orientar a interpretação e compreensão do sistema constitucional instaurado em 1988"21. Desta forma, o princípio da dignidade humana se projeta por toda a Constituição, servindo como critério de interpretação para o ordenamento jurídico brasileiro.

\section{O DIREITO HUMANO À ÁGUA}

O debate acerca da relação do homem com o meio natural se intensificou nas últimas décadas, resultando em um grande rol de convenções internacionais que, de alguma forma, abordam as questões relativas aos problemas ambientais. Este processo se deu a partir dos anos 1960 com a rápida industrialização e o crescimento desordenado dos aglomerados urbanos e dos modos de produção a partir de u4ma perspectiva puramente economicista que colocou os Estados e a

\footnotetext{
${ }^{19}$ ALVES, J. A. Lindgren. Os direitos humanos como tema global. São Paulo: Fundação Alexandre Gusmão, 1994, p. 104.

${ }^{20}$ PIOVESAN, Flávia. Temas de direitos humanos / Flávia Piovesan - 5. ed. - São Paulo: Saraiva, 2012. p. 148.

${ }^{21}$ Ibidem, p. 171.
} 
comunidade internacional perante a evidência de que os recursos naturais não são inesgotáveis ${ }^{22}$.

Esta dinâmica passou a impor compromissos aos Estados e instituições no que diz respeito à elaboração de políticas públicas para o desenvolvimento da gestão ambiental, impactando diretamente no bemestar dos cidadãos. Dentre os recursos ambientais mais afetados pela ação humana está a água, objeto central para este trabalho, elemento essencial para o desenvolvimento dos Estados e para a manutenção da vida, fortalecendo o meio ambiente saudável como um direito fundamental inerente ao ser humano.

O desenvolvimento da governança da água no mundo se intensificou a partir dos anos 1970, com a intensificação dos problemas de escassez e poluição dos recursos hídricos, o que levou a esforços e iniciativas por parte da comunidade internacional, conforme aponta José Esteban Castro: "the challenges facing water management have become increasingly global in scope since the 1970s [...] the international community has lanched significant and far-reching policy iniciatives in response to the challenges"23. Tais iniciativas políticas levaram à realização de conferências e declarações que, no tocante ao tema da água, tiveram grande impacto, como a Conferência de Mar del Plata, de 1977, a Conferência Internacional sobre Água e Meio Ambiente (CIAMA, 1992) e a Conferência das Nações Unidas sobre Meio Ambiente e Desenvolvimento (CNUMAD, 1992).

A abordagem da água como um direito humano ainda é algo recente, mas, tendo em vista sua essencialidade para a vida e para o bemestar do ser humano, faz-se necessária esta abordagem. Alguns autores tratam questões relativas ao meio ambiente na ótica dos direitos humanos desde os anos 1990, como Antônio Augusto Cançado Trindade: "impõe-se que seja dado em particular à questão da relação entre os direitos humanos e a proteção ambiental um tratamento sistematizado, dada a sua transcendental importância em nossos dias. Embora tenham os domínios da proteção do ser humano e da proteção ambiental sido tratados até o

\footnotetext{
${ }^{22}$ CANOTILHO, José Joaquin Gomes. Protecção do ambiente e direito de propriedade (crítica de jurisprudência ambiental). Coimbra Editora: Coimbra, 1995, p. 11-10.

${ }^{23}$ Os desafios que a gestão da água enfrenta se tornaram cada vez mais globais a partir dos anos 1970, [...] a comunidade internacional lançou significativas iniciativas políticas de longo alcance em resposta a estes desafios (tradução livre). CASTRO, Jose Esteban. Water governance in the twentieth first century. Ambiente \& Sociedade. Campinas. V. X, n. 2, p. 97-118, 2007, p. 97.
} 
presente separadamente, é necessário buscar maior aproximação entre eles" 24 .

Desta forma, estando a água intrinsecamente ligada às questões ambientais, este capítulo analisará brevemente o desenvolvimento do conceito de direito humano à água a partir de convenções internacionais e da Resolução 64/292, da Assembleia Geral da Organização das Nações Unidas, que reconheceu o acesso à água potável e o saneamento como um direito fundamental. Também serão estudados outros precedentes que abordam o acesso à água pelos cidadãos, bem como algumas bases legais para a consolidação desta abordagem da agua como um direito humano no Brasil.

\subsection{O DIREITO HUMANO À ÁGUA E SEU RECONHECIMENTO}

O século XXI se iniciou com uma das condições mais fundamentais para o desenvolvimento humano não sendo atingida: o acesso universal a serviços básicos de água, sendo este uma das maiores falhas da comunidade internacional no século $\mathrm{XX}^{25}$. A partir de um processo sobre o desenvolvimento da política global da água apontado por Peter P. Mollinga ${ }^{26}$, a abordagem dos recursos hídricos sobre uma ótica dos direitos humanos tornou-se necessária, já que estes são considerados um "marco conceitual do desenvolvimento humano" 27 , entendendo-se que as desigualdades no que diz respeito às condições de vida humanas são um obstáculo imposto ao avanço do desenvolvimento.

Tendo em vista que os instrumentos dos direitos humanos estão em constante evolução e são ajustados de acordo com as transformações que o homem faz sobre a natureza e as relações sociais ${ }^{28}$ e as novas preocupações em relação ao bem-estar dos cidadãos com o surgimento dos direitos de terceira geração, abordados no primeiro capítulo desta pesquisa, fez-se necessária uma nova abordagem sobre a água como um direito

\footnotetext{
${ }^{24}$ CANÇADO TRINDADE, Antônio Augusto. Direitos humanos e meio-ambiente: paralelo dos sistemas de proteção internacional. Porto Alegre: Sergio Antonio Fabris Editor, 1993, p. 23.

${ }^{25}$ GLEICK, Peter H. The Human Right to Water.Water Policy.Vol. 1. n. 1, p. 487-503, 1998, p. 488.

${ }^{26}$ MOLLINGA, Peter P. Water, Politics and Development: Framing a Political Sociology of Water Resources Management. Water Alternatives. V. 1, n. 1, p. 7-23, 2008, p. 13.

${ }^{27}$ ZORZI, L., TURATTI, L.; MAZZARINO, J. M. O direito humano de acesso à água potável: uma análise continental baseada nos Fóruns Mundiais da Água. Rev. Ambiente \& Água [online]. vol.11, n.4, pp. 954-97. Taubaté, 2016, p. 955.

${ }^{28}$ CANÇADO TRINDADE, Antônio Augusto. op. cit.
} 
humano. Este direito tem como principal fundamentação "a premissa de que o acesso à água é uma precondição indispensável para alcançar os demais direitos humanos" 29 .

Os grandes documentos publicados ao longo dos anos nos quais os direitos humanos se desenvolveram, como a Carta Internacional de Direitos Humanos, a Declaração Universal de Direitos Humanos, o Pacto Internacional sobre Direitos Econômicos, Sociais e Culturais, e o Pacto Internacional sobre Direitos Civis e Políticos, não mencionaram, em nenhum momento, o reconhecimento do direito humano à água ${ }^{30}$ propriamente dito.

Porém, algumas convenções já haviam abordado o direito à água, mesmo que o inserindo entre outros direitos, como o direito ao meio ambiente saudável, por exemplo. Primeiramente, dentre estas convenções, cabe destaque à Convenção de Genebra de 1949 que, ao discorrer sobre direitos de prisioneiros de guerra afirmava, em seu artigo 20, que: "A Potência detentora fornecerá aos prisioneiros de guerra evacuados água potável e alimentação suficiente, assim como fatos e os cuidados médicos necessários" "31. Outra importante Convenção neste sentido é a Convenção sobre a Eliminação de Todas as Formas de Discriminação Contra a Mulher, de 1979, que em seu texto, no artigo 14, parágrafo $2^{\circ}$, evidencia diretamente um esboço para um direito à água:

Art, 14.2: Os Estados-Partes adotarão todas as medidas apropriadas para eliminar a discriminação contra a mulher nas zonas rurais, a fim de assegurar, em condições de igualdade entre homens e mulheres, que elas participem no desenvolvimento rural e dele se beneficiem, e em particular assegurar-lhes-ão o direito a: [...] h) gozar de condições de vida adequadas, particularmente nas esferas da habitação, dos serviços sanitários, da eletricidade e do abastecimento de água, do transporte a das comunicações ${ }^{32}$.

\footnotetext{
${ }^{29}$ VILLAR, Pilar Carolina; RIBEIRO, Wagner Costa. A Percepção do Direito Humano à Água na Ordem Internacional. Revista de Direitos Humanos Fundamentais e Democracia. Curitiba, v. 11, n. 11, p 358-380, jan./jun. 2012, p. 361.

${ }^{30}$ VILLAR, Pilar Carolina; RIBEIRO, Wagner Costa. A Percepção do Direito Humano à Água na Ordem Internacional. Revista de Direitos Humanos Fundamentais e Democracia. Curitiba, v. 11, n. 11, p 358-380, jan./jun. 2012, p. 361.

${ }^{31}$ BRASIL. Decreto no 42.121, de 21 de Agôsto de 1957. Promulga as Convenções concluídas em Gênebra, a 12 de agôsto de 1949, destinadas a proteger as vítimas da guerra. Rio de Janeiro, 1957.

${ }^{32}$ BRASIL. Decreto ${ }^{\mathbf{0}}$ 4.377, de 13 de Setembro de 2002. Promulga a Convenção sobre a Eliminação de Todas as Formas de Discriminação Contra a Mulher, de 1979. Brasília, 2002.
} 
Por sua vez, conforme destaca por Pierre-Marie Dupuy, cabe destaque também à Convenção sobre os Direitos da Criança, de 1989, que "fait obligation aus Parties de lutter contre la maladie et la malnutrition grâce a la forniture d'aliments nutritifs e d'eau potable"33 , elencando os direitos à água e a alimentação como essenciais ao direito à saúde das crianças. Tais dizeres estão evidenciados no artigo 24 , parágrafo $2^{\circ}$, da Convenção que discorre a respeito do direito da criança de gozar do melhor padrão possível de vida. A saber:

Art. 24.2: Os Estados Partes garantirão a plena aplicação desse direito e, em especial, adotarão as medidas apropriadas com vistas a: [...] c) combater as doenças e a desnutrição dentro do contexto dos cuidados básicos de saúde mediante, inter alia, a aplicação de tecnologia disponível e o fornecimento de alimentos nutritivos e água potável, tendo em vista os perigos e riscos da poluição ambiental $^{34}$.

Ainda neste escopo, Ribeiro e Villar destacam também a necessidade de se garantir o acesso à água para fins de higiene e alimentação, bem como o acesso à água portável quando necessário, por parte das Regras Mínimas para o Tratamento de Reclusos adotadas pelo Primeiro Congresso das Nações Unidas Sobre Prevenção do Crime e do Tratamento dos Delinquentes, de $1955^{35}$.

Como previamente mencionado, a política da água se intensificou nos anos 1970 e a sua inserção nas grandes conferências, declarações, convenções e tratados foi ampliada. Desta forma, a Declaração de Estocolmo, de 1972, resultante da Conferência das Nações Unidas para o Desenvolvimento Humano, abordou novamente o direito de acesso à água, atrelando-o ao meio ambiente saudável e exigindo ação política por parte dos Estados participantes da Conferência, em seus princípios 1 e 2:

\footnotetext{
${ }^{33}$ É vinculativo às partes combates as doenças e a desnutrição através do fornecimento de alimentos nutritivos e água potável (tradução livre) (DUPUY, Pierre Marie. Le droit à l'eau, um droit international. European University Institute Working Paper. Law n. 2006/06. Italy: European University Institute, 2006. Disponível em: https://cadmus.eui.eu/bitstream/handle/1814/4252/LAW\%202006.6\%20Dupuy.pdf?sequence=1\&isA llowed=y>. Acesso em: 20 jun. 2019, p. 2).

${ }^{34}$ BRASIL. Decreto n ${ }^{\mathbf{9}}$ 99.710, de 21 de Novembro de 1990. Promulga a Convenção sobre os Direitos da Criança. Brasília, 1990.

${ }^{35}$ VILLAR, Pilar Carolina; RIBEIRO, Wagner Costa. A Percepção do Direito Humano à Água na Ordem Internacional. Revista de Direitos Humanos Fundamentais e Democracia. Curitiba, v. 11, n. 11, p 358-380, jan./jun. 2012, p. 362
} 
1. O homem tem o direito fundamental à liberdade, à igualdade, e ao desfrute de condições de vida adequadas e um meio ambiente de qualidade tal que lhe permita levar uma vida digna e gozar de bemestar, tendo a solene obrigação de proteger e melhorar o meio ambiente para as gerações presentes e futuras.

2. Os recursos naturais da terra, incluídos o ar, a água, a terra, a flora e a fauna e especialmente as amostras representativas dos ecossistemas naturais devem ser preservados em benefício das gerações futuras, mediante planificação ou ordenamento ${ }^{36}$.

Assim, nos anos 1990, o assunto da água como um bem indispensável para a manutenção da vida e para o desenvolvimento continuou sendo abordado por Conferências e Declarações. Dentre estas, destacam-se a Conferência Internacional sobre Água e Meio Ambiente, realizada em Dublin no ano de 1992, e a Conferência das Nações Unidas sobre Meio Ambiente e Desenvolvimento, realizada no Rio de Janeiro, também em $1992^{37}$.

A Organização das Nações Unidas demonstrou um papel importante no que diz respeito à consolidação da água como um direito humano fundamental atuando em Conferências, emitindo pareceres e declarações, tendo em vista sua essencial participação ao lançar os anos entre 1980 e 1990 como década internacional da Água e do Saneamento. Também, destaca-se a atuação da Organização a declaração do ano de 2003 como o Ano Internacional da Água e 2008 como o ano Internacional do Saneamento Básico, levando em consideração os Objetivos do Milênio e a Cúpula Mundial sobre Desenvolvimento Sustentável de Johanesburgo $(2002)^{38}$.

No ano de 2002, também cabe destaque ao Comentário Geral n ${ }^{\circ}$ 15 da Organização das Nações Unidas, que reinterpretou o Pacto Internacional sobre Direitos Econômicos, Sociais e Culturas, especialmente nos artigos 11 e 12. Por meio desta reinterpretação, a Organização das Nações Unidas inseriu o direito à água nas diretrizes estabelecidas pelo Pacto, tendo em vista as lacunas deixadas pelos dois artigos mencionados ao tratarem do direito a um nível de vida adequado e o grau de saúde mais elevado possível, estipulando aos Estados signatários

\footnotetext{
${ }^{36}$ ORGANIZAÇÃO DAS NAÇÕES UNIDAS. Declaração de Estocolmo sobre Meio Ambiente Humano. Estocolmo, 1972.

${ }^{37}$ LE PRESTRE, Philippe. Ecopolítica Internacional. $2^{\text {a }}$ Ed. Jacob Gorender (Trad.). São Paulo: Editora Senac São Paulo, 2005.

${ }^{38}$ VILLAR, Pilar Carolina; RIBEIRO, Wagner Costa. A Percepção do Direito Humano à Água na Ordem Internacional. Revista de Direitos Humanos Fundamentais e Democracia. Curitiba, v. 11, n. 11, p 358-380, jan./jun. 2012, p. 364.
} 
do pacto as obrigações com o direito à água. $\mathrm{O}$ principal argumento para tal inserção utilizado pela ONU foi o fato de que "o direito humano à água é indispensável para se viver uma vida com dignidade humana", sendo este "um requisito para a realização de outros direitos humanos" 39 .

Pela primeira vez direito humano à água foi formalmente reconhecido, como previamente mencionado, pela Resolução 64/292 da Assembleia Geral da ONU, de 2010. A Resolução reconheceu que a água potável e limpa e o saneamento são essenciais para a concretização dos demais direitos humanos, apelando aos Estados e organizações internacionais para efetivarem ações para tal. Esta Resolução reconheceu o Direito Humano à Água e ao Saneamento e:

1. Declares the right to safe and clean drinking water and sanitation as a human right that is essential for the full enjoyment of life and all human rights;

2. Call upon states and international organizations to provide financial resources, capacity-building and technology transfer, through international assistance and cooperation, in particular to developing countries, in order to scale up efforts to provide safe, clean, accessible and affordable drinking water and sanitation for $\mathrm{all}^{40}$.

Na sequência, ainda no âmbito das iniciativas das Nações Unidas, no mesmo ano de 2010, o Conselho dos Direitos Humanos da Organização publicou a Resolução 15/9 afirmando que os direitos à água e ao saneamento de qualidade são partes integrantes do direito internacional e que esses direitos são vinculativos aos Estados, devendo estes tomarem iniciativas para efetivá-los ${ }^{41}$. A Resolução retomou documentos como a Declaração Universal de Direitos Humanos, o Pacto Internacional de

${ }^{39}$ ORGANIZAÇÃO DAS NAÇÕES UNIDAS. O Direito Humano à Água e Saneamento - Marcos. Disponível em: <https://www.un.org/waterforlifedecade/pdf/human_right_to_water_and_sanitation_milestones_por.p df>. Acesso em 15 jul. 2019.

40 1. Declara o direito à água potável e segura e ao saneamento como um direito humano essencial para o pleno desfrute da vida e de todos os direitos humanos;

2. Induz os Estados e organizações internacionais a fornecer recursos financeiros, capacitação e transferência de tecnologia, por meio de assistência internacional e cooperação, especialmente aos países em desenvolvimento, a fim de ampliar os esforços para fornecer água potável segura, limpa, acessível e saneamento para todos (tradução livre).

${ }^{41}$ ORGANIZAÇÃO DAS NAÇÕES UNIDAS. O Direito Humano à Água e Saneamento - Marcos. Disponível em: $<$ https://www.un.org/waterforlifedecade/pdf/human_right_to_water_and_sanitation_milestones_por.p df>. Acesso em 15 jul. 2019. 
Direitos Econômicos, Sociais e Culturais, o Pacto Internacional de Direitos Civis e Políticos, a Convenção sobre os Direitos da Criança e a Convenção sobre a Eliminação de Todas as Formas de Discriminação Contra a Mulher para ressaltar a necessidade de consideração e implementação do direito humano à água para a efetivação dos demais direitos humanos ${ }^{42}$.

Desta forma, foram apresentados os antecedentes e os principais marcos que levaram ao reconhecimento internacional do direito humano à água, ainda que estas declarações não vinculem os Estados juridicamente. Isto demonstra os esforços realizados pela Organização das Nações Unidas para resguardo do direito à vida. Neste sentido, cabe acrescentar também a relação intrínseca da água com o meio ambiente, com o desenvolvimento, com a saúde e, em linhas gerais, com o bem-estar humano, que tornam evidente a inserção da água dentre as necessidades básicas para o homem e em respeito ao direito à vida. Este direito, de acordo com Antônio Augusto Cançado Trindade, tem de ser elevado a um direito supremo do ser humano e condição necessária para o exercício de qualquer outro direito $^{43}$. O referido autor também destaca a necessidade da redução dos problemas ambientais para a consolidação de tal direito, sendo que, nesse contexto de degradação ambiental, "se sustentou o direito à vida em sua ampla dimensão, abarcando as condições dignas e adequadas de vida, e se levaram em consideração os efeitos de tais problemas sobre o meioambiente e sobre a saúde humana ao mesmo tempo, conjuntamente"44.

\subsection{ABORDAGENS SOBRE O REGIME JURÍDICO DAS ÁGUAS E O DIREITO HUMANO À ÁGUA NO BRASIL}

A proteção jurídica das águas brasileiras tem suas diretrizes gerais estabelecidas pela Constituição Federal de 1988, conforme destacam Aith e Rothbarth: "o Estatuto Jurídico das Águas no Brasil tem suas bases na CF 88 e abrange, de um lado, a proteção dos direitos humanos e, de outro, a proteção do meio ambiente e dos recursos hídricos e naturais"45.

\footnotetext{
${ }^{42}$ UNITED NATIONS - General Assembly. Resolution Adopted by the Humans Rights Council A/HRC//RES/15/9. Disponível em: https://www.un.org/ga/search/view_doc.asp?symbol=A/HRC/RES/15/9>. Acesso em 20 jul. 2019.

${ }^{43}$ CANÇADO TRINDADE, Antônio Augusto. Direitos humanos e meio-ambiente: paralelo dos sistemas de proteção internacional. Porto Alegre: Sergio Antônio Fabris Editor, 1993.

${ }^{44}$ Ibidem.

${ }^{45}$ AITH, Fernando Mussa Abujamra; ROTHBARTH, Renata. O estatuto jurídico das águas no Brasil.
} Estudos Avançados, v. 29, n. 84, p. 163-177, 2015, p. 165-166. 
Como afirma João Marcos Adede y Castro, deve-se observar que o que rege a legislação de recursos hídricos é o rol de direitos fundamentais expressos na Constituição Federal de 1988, como o direito à vida, à segurança e à dignidade ${ }^{46}$, tendo em vista que a interpretação e aplicação de normas de recursos hídricos deve considerar a água como um bem que gera qualidade e condições básicas de vida.

Desta forma, assim como os direitos humanos elencados pela Constituição Federal em geral, a água deve ser vista como um direito indivisível, pois esta é necessária para a consolidação dos demais direitos e os objetivos fundamentais da República Federativa do Brasil - contidos no artigo $3^{\circ}$ (a construção de uma sociedade livre, justa e solidária; o desenvolvimento nacional; a erradicação da pobreza; e a promoção do bem de todos) - devem ser respeitados. Para tal, embora a Constituição Federal de 1988 "não reconheça a água como um direito humano fundamental, oferece um conjunto de dispositivos que garantem uma proteção especial a este bem jurídico constitucionalmente tutelado" ${ }^{47}$.

Quanto à natureza jurídica, há uma fragmentação no que diz respeito à tutela da água no Brasil pois diferentes códigos abordam questões relativas à água, ainda que se tenha promulgada a Lei $\mathrm{n}^{\circ} 9.433$ que estabeleceu a Política Nacional de Recursos Hídricos. Outros diplomas legais também discorrem sobre as águas, como a Política Nacional de Saneamento Básico, o Código Civil e a previamente mencionada Constituição. Assim, a Constituição Federal a caracteriza como um bem público juridicamente tutelado, distribuindo a dominialidade dos corpos hídricos no país:

Art. 20: São bens da União: [...] III - os lagos, rios e quaisquer correntes de água em terrenos de seu domínio, ou que banhem mais de um Estado, sirvam de limites com outros países, ou se estendam a território estrangeiro, bem como os terrenos marginais e praias fluviais ${ }^{48}$.

A mesma também delimita as águas de titularidade dos estados: “Art. 26: Incluem-se entre os bens dos Estados: I - As águas superficiais

\footnotetext{
${ }^{46}$ CASTRO, João Marcos Adede y. Regime jurídico das águas no Brasil. Revista do Ministério Público do RS. n. 65, jan. 2010, p. 30.

${ }^{47}$ AITH, Fernando Mussa Abujamra; ROTHBARTH, Renata. O estatuto jurídico das águas no Brasil.

Estudos Avançados, v. 29, n. 84, p. 163-177, 2015, p. 167.

${ }^{48}$ BRASIL. Constituição da República Federativa do Brasil de 1988. Brasília, 1988.
} 
ou subterrâneas, fluentes, emergentes e em depósito, ressalvadas, nesse caso, na forma da lei, as decorrentes de obras da União" ${ }^{\text {"49 }}$.

No que diz respeito à legislação sobre águas no Brasil, cabe destaque ao Código de Águas, instituído no país por meio do Decreto número 24.643 de 1934, que determinava que o domínio sobre as águas era dos possuidores das terras onde estas se encontravam, estabelecendo uma ideia de "águas particulares" - o que atualmente está revogado, tendo em vista que a água e o meio ambiente são bens de todos ${ }^{50}$. O Código de Águas é um marco importante, pois, além de ter criado as primeiras ideias de instrumentos de controle da exploração das águas (principalmente as subterrâneas, pelo seu artigo 98), atribuiu aos "donos" das águas a responsabilidade pela despoluição ${ }^{51}$.

Atualmente, as normas para a gestão da água estão definidas na Lei Federal $n^{\circ}$ 9.433, que instaurou a Política Nacional de Recursos Hídricos. A referida lei adota como princípios de gestão das águas a abordagem da água como bem de domínio e a valoração econômica e, ao mesmo tempo, define como prioridade o uso humano e dessedentação de animais tendo como instrumentos de gestão e controle, entre outros, a outorga dos direitos de uso e a cobrança pelo uso. Tais princípios estão expressos logo no artigo $1^{\circ}$ e $5^{\circ}$ da Lei:

\footnotetext{
Art. $1^{\circ}$ A Política Nacional de Recursos Hídricos se baseia nos seguintes fundamentos:

I - a água é um bem de domínio público;

II - a água é um recurso natural limitado, dotado de valor econômico;

III - em situações de escassez, o uso prioritário dos recursos hídricos é o consumo humano e a dessedentação de animais [...]

Art. $5^{\circ}$ São instrumentos da Política Nacional de Recursos Hídricos:

$[\ldots]$

III - a outorga dos direitos de uso dos recursos hídricos;

IV - a cobrança pelo uso dos recursos hídricos ${ }^{52}$.
}

É importante destacar que o texto legal reitera o posicionamento da água como um bem de domínio público, o que pode ser destacado como uma premissa para o reconhecimento do direito humano a água, tendo em

\footnotetext{
${ }^{49}$ Ibidem.

${ }^{50}$ CASTRO, João Marcos Adede y. Regime jurídico das águas no Brasil. Revista do Ministério Público do RS. n. 65, jan. 2010, p. 31-32.

${ }^{51}$ Ibidem, p. 32.

${ }^{52}$ BRASIL. Lei no 9.433, de 8 de Janeiro de 1997. Institui a Política Nacional de Recursos Hídricos (PNRH). Brasília, 1997.
} 
vista que "a dominialidade pública da água, afirmada na Lei n 9.433/97, não transforma o Poder Público federal em proprietário da água, mas tornao gestor desse bem, do interesse de todos" ${ }^{\text {"53 }}$.

Neste momento, cabe destaque aos apontamentos que alguns autores fazem em relação a inserção da água na economia de mercado, tendo em vista a necessidade de este recurso ser tratado como um direito humano. O que é apontado é que a submissão da água às regras do mercado seria submeter um bem fundamental à lei da oferta e da procura e à análise de custos e benefícios, e isto acarreta a impossibilidade de pagar que ocasiona na falta de acesso ao recurso por parte das pessoas menos favorecidas, tendo em vista que "a racionalidade do mercado não vê empecilhos em excluir aqueles que não pagam" "54, o que também entra em conflito com a ideia de bem público ${ }^{55}$. Neste sentido, deve observar-se que a lógica econômica e a lógica dos direitos humanos apresentam grandes distinções.

Por fim, tendo em vista a fragmentação normativa do estatuto da legislação sobre as águas no Brasil, com normas vigentes desde do Código de Águas de 1934, da Política Nacional de Recursos Hídricos de 1997, da Política Nacional de Saneamento Básico, de 2007, se tem um grande e complexo quadro regulatório ${ }^{56}$. Esta fragmentação também evidencia "ausência de uma boa organização jurídico-administrativa do setor" ${ }^{57}$ e, para que se tenha uma proteção efetiva ao direito humano à água no país são necessárias atualizações das normas jurídicas mais antigas e obsoletas ${ }^{58}$ por meio do reconhecimento e adoção de normas internacionais, tendo em vista a participação do Brasil com uma posição de protagonismo nas grandes conferências sobre meio ambiente e o fato de o Brasil ser signatário de Convenções e tratados que fazem menção ao direito à água, como a Convenção sobre os Direitos da Criança e a Convenção sobre a Eliminação de Todas as Formas de Discriminação Contra a Mulher.

\footnotetext{
${ }^{53}$ MACHADO, Paulo Afonso Leme. Recursos hídricos: Direito Brasileiro e Internacional. São Paulo: Malheiros, 2002, p. 414.

${ }^{54}$ VILLAR, Pilar Carolina; RIBEIRO, Wagner Costa. A Percepção do Direito Humano à Água na Ordem Internacional. Revista de Direitos Humanos Fundamentais e Democracia. Curitiba, v. 11, n. 11, p 358-380, jan./jun. 2012, p. 372.

${ }^{55}$ Ibidem, p. 373.

${ }^{56}$ AITH, Fernando Mussa Abujamra; ROTHBARTH, Renata. O estatuto jurídico das águas no Brasil. Estudos Avançados, v. 29, n. 84, p. 163-177, 2015, p. 174-175.

${ }^{57}$ Ibidem, p. 175.

${ }^{58}$ Ibidem.
} 


\section{5}

\section{CONSIDERAÇÕES FINAIS}

Este trabalho buscou analisar a abordagem da água como um direito humano fundamental no Brasil guiado pela hipótese de que a primazia dos direitos humanos no país pode levar a adoção do conceito de direito humano à água pelo ordenamento jurídico pátrio.

Assim, foram tratados os direitos humanos a partir da exposição dos precedentes históricos e do surgimento de um Direito Internacional dos Direitos Humanos. Foram estudados também os principais documentos criados como fontes deste Direito, como a Declaração Universal de Direitos Humanos de 1948, bem como o protagonismo da Organização das Nações Unidas em iniciativas para a elaboração de tratados internacionais sobre direitos humanos, como o Pacto Internacional de Direitos Civis e Políticos e o Pacto Internacional de Direitos Econômicos, Sociais e Culturais, ambos de 1966.

Foi feito o estudo sobre o posicionamento dos direitos humanos no ordenamento jurídico brasileiro, tendo em vista a redemocratização do país com o fim do governo militar, a partir da Constituição Federal de 1988 que, além de elencar uma série de direitos fundamentais, abre espaço para que novos direitos sejam adotados pelo ordenamento jurídico brasileiro. Desta forma, também foi analisado o procedimento legislativo para que este feito seja possível a partir da votação dos tratados internacionais de direitos humanos prevista no Artigo $5^{\circ}$ da Constituição Federal por meio de um dispositivo inserido pela Emenda Constitucional n ${ }^{\circ} 45$, de 2004.

Por fim, foi feito o estudo do direito humano à água propriamente dito. Tal direto passou a ser reconhecido com a intensificação do desenvolvimento das políticas ambientais e, especificamente, da política de gestão da água, ainda que algumas convenções internacionais já abordavam a água como um direito humano, mesmo que inserindo-o entre outros direitos. Dentre estas convenções foram destacadas a Convenção de Genebra, de 1949, a Convenção sobre a Eliminação de Todas as Formas de Discriminação Contra a Mulher, de 1979, e a Convenção sobre os Direitos da criança, de 1989.

Foi feita a abordagem sobre o regime jurídico das a águas no Brasil, destacando também as premissas para o reconhecimento da água como um direito humano, tendo em vista que a interpretação e aplicação da legislação de recursos hídricos vigente são feitas à luz da Constituição Federal e devem considerar a água como um bem essencial à consolidação dos demais direitos fundamentais elencados no texto constitucional. 
Desta forma, dada a essencialidade da água para a manutenção da vida e para a satisfação das mais básicas necessidades, seu fornecimento em quantidade e qualidade adequados deve ser uma prioridade na agenda política brasileira. Esta garantia do acesso à água e ao saneamento como direito humano fundamental ainda é dificultada por alguns fatores, como a abordagem econômica da água e a ideia do full-cost recovery que se tem na gestão das águas. Mesmo diante tal cenário podem ser constatados alguns avanços no sentido do reconhecimento e consolidação do direito humano à água, como o reconhecimento internacional a partir das iniciativas da Organização das Nações Unidas e, no caso brasileiro, o regime jurídico das águas, tratado no último capítulo, e a grande importância dada aos direitos humanos por todo o ordenamento jurídico do país a partir da Constituição Federal.

\section{REFERÊNCIAS}

AITH, Fernando Mussa Abujamra; ROTHBARTH, Renata. O estatuto jurídico das águas no Brasil. Estudos Avançados, v. 29, n. 84, p. 163-177, 2015.

ALVES, J. A. Lindgren. Os direitos humanos como tema global. São Paulo: Fundação Alexandre Gusmão, 1994.

BATISTA, Vanessa Oliveira; RODRIGUES, Luciana Boiteux de Figueiredo; PIRES, Thula Rafaela. A Emenda Constitucional $n^{\circ} 45 / 2004$ e a constitucionalização dos tratados internacionais de direitos humanos no Brasil. Revista Jurídica Brasileira, Brasília, v. 10, n. 90, p. 01-44. Abr./maio 2008.

BILDER, Richard B. An overview of international human rights law. In: HANNUM, Hurst, Ed. Guide to international human rights practice. $2^{\mathrm{a}}$ ed. Philadelphia, University of Pennsylvania Press. 1992.

BONAVIDES, Paulo. Curso de direito constitucional. 15ª ed. São Paulo: Malheiros, 2004.

BRASIL. Constituição da República Federativa do Brasil de 1988. Brasília, 1988.

Decreto ${ }^{\circ}$ 4.377, de 13 de Setembro de 2002. Promulga a Convenção sobre a Eliminação de Todas as Formas de Discriminação Contra a Mulher, de 1979. Brasília, 2002.

Decreto ${ }^{\circ}$ 42.121, de 21 de Agôsto de 1957. Promulga as Convenções concluídas em Gênebra, a 12 de agôsto de 1949, destinadas a proteger as vítimas da guerra. Rio de Janeiro, 1957.

Decreto $\mathrm{N}^{\circ}$ 591, de 6 de Julho de 1992. Atos Internacionais. Pacto Internacional sobre

Direitos Econômicos, Sociais e Culturais. Promulgação. Brasília, 1992. 
Decreto $\mathrm{N}^{\circ}$ 592, de 6 de Julho de 1992. Atos Internacionais. Pacto Internacional sobre Direitos Civis e Políticos. Promulgação. Brasília, 1992.

. Decreto ${ }^{\circ}$ 99.710, de 21 de Novembro de 1990. Promulga a Convenção sobre os Direitos da Criança. Brasília, 1990.

Lei ${ }^{\circ}$ 9.433, de 8 de Janeiro de 1997. Institui a Política Nacional de Recursos Hídricos (PNRH). Brasília, 1997.

BUERGENTHAL, Thomas; SHELTON, Dinah; STEWART, David P. International Human Rights in a Nutshell. George Washington University Law School Legal Studies Paper, 4 ed, 2009.

CANÇADO TRINDADE, Antônio Augusto. A interação entre o direito internacional e o direito interno na proteção dos direitos humanos. In: Arquivos do Ministério da Justiça, Brasília, v. 46. N. 182. p. 52-53, jul./dez. 1993.

. Direitos humanos e meio-ambiente: paralelo dos sistemas de proteção internacional. Porto Alegre: Sergio Antônio Fabris Editor, 1993.

CANOTILHO, J. J. Gomes. Direito constitucional. Coimbra: Almedina, 1995.

Protecção do ambiente e direito de propriedade (crítica de jurisprudência ambiental). Coimbra Editora: Coimbra, 1995.

CASTRO, João Marcos Adede y. Regime jurídico das águas no Brasil. Revista do Ministério Público do RS. n. 65, jan. 2010.

CASTRO, Jose Esteban. Water governance in the twentieth first century. Ambiente \& Sociedade. Campinas. V. X, n. 2, p. 97-118, 2007.

DUPUY, Pierre Marie. Le droit à l'eau, um droit international. European University Institute Working Paper. Law n. 2006/06. Italy: European University Institute, 2006. Disponível em: < https://cadmus.eui.eu/bitstream/handle/1814/4252/LAW\%202006.6\%20Dupuy.pdf?sequence=1\&isA llowed=y >. Acesso em: 20 jun. 2019.

GLEICK, Peter H. The Human Right to Water.Water Policy.Vol. 1. n. 1, p. 487-503, 1998.

HEYNS, Christof; PADILLA, David; ZWAAK, Leo. A schematic comaprison of regional human rights systems. African Human Rights Law Journal. Vol. 3. 2003.

HUNT, Lynn. A invenção dos direitos humanos. $1^{\text {a }}$ ed. São Paulo: Companhia das Letras, 2009.

LAFER, Celso. A reconstrução dos direitos humanos: um diálogo com o pensamento de Hannah Arendt. São Paulo: Companhia das Letras, 1991.

LE PRESTRE, Philippe. Ecopolítica Internacional. $2^{a}$ Ed. Jacob Gorender (Trad.). São Paulo: Editora Senac São Paulo, 2005. 
MACHADO, Antônio Alberto. Elementos de teoria dos direitos fundamentais. $1^{\mathrm{a}}$ ed. Cultura Acadêmica Editora: São Paulo, 2017.

MACHADO, Costa (org.) FERRAZ, Anna Candida da Cunha. Constituição Federal interpretada: artigo por artigo, parágrafo por parágrafo. $6^{\mathrm{a}}$ ed. Barueri: Manole, 2015.

MACHADO, Paulo Afonso Leme. Recursos hídricos: Direito Brasileiro e Internacional. São Paulo: Malheiros, 2002.

MELLO, Celso D. de Albuquerque. Curso de direito internacional público. 10ª ed. Rio de Janeiro: Renovar, 1994.

MOLLINGA, Peter P. Water, Politics and Development: Framing a Political Sociology of Water Resources Management. Water Alternatives. V. 1, n. 1, p. 7-23, 2008.

NAÇÕES UNIDAS. A Declaração Universal dos Direitos Humanos. Disponível em: <https://nacoesunidas.org/direitoshumanos/declaracao/>. Acesso em: 30 mai. 2019.

ONU - Organização das Nações Unidas. O Direito Humano à Água e Saneamento. Disponível em: http://www.un.org/waterforlifedecade/pdf/human_right_to_water_and_sanitation_media_brief_por.p df. Acesso em 15 mar. 2018.

ORGANIZAÇÃO DAS NAÇÕES UNIDAS - ONU. Carta de São Francisco. São Francisco, 1945.

. Declaração de Estocolmo sobre Meio Ambiente Humano. Estocolmo, 1972.

O Direito Humano à Água e Saneamento - Marcos. Disponível em:

$\langle$ https://www.un.org/waterforlifedecade/pdf/human_right_to_water_and_sanitation_milestones_por.p df>. Acesso em 15 jul. 2019.

O Direito Humano à Água e Saneamento. Disponível em:

$\langle$ http://www.un.org/waterforlifedecade/pdf/human_right_to_water_and_sanitation_media_brief_por. pdf>. Acesso em 15 jul. 2019.

PIOVESAN, Flávia. Direitos humanos e o direito constitucional internacional. $9^{a}$ ed. São Paulo: Saraiva, 2008.

. Temas de direitos humanos / Flávia Piovesan - 5. ed. - São Paulo: Saraiva, 2012.

RAMOS, André de Carvalho. Teoria geral dos direitos humanos na ordem internacional. $2^{\mathrm{a}}$ ed. São Paulo: Saraiva, 2012.

TUNDISI, J. G. Recursos Hídricos no Futuro: Problemas e Soluções. Estudos Avançados, v. 22, n. 63. São Paulo, 2008.

UNITED NATIONS - General Assembly. Resolution Adopted by the Humans Rights Council A/HRC//RES/15/9. Disponível em: < https://www.un.org/ga/search/view_doc.asp?symbol=A/HRC/RES/15/9>. Acesso em 20 jul. 2019. 
VILLAR, Pilar Carolina; RIBEIRO, Wagner Costa. A Percepção do Direito Humano à Água na Ordem Internacional. Revista de Direitos Humanos Fundamentais e Democracia. Curitiba, v. 11, n. 11, p 358-380, jan./jun. 2012.

ZORZI, L., TURATTI, L.; MAZZARINO, J. M. O direito humano de acesso à água potável: uma análise continental baseada nos Fóruns Mundiais da Água. Rev. Ambiente \& Água [online]. vol.11, n.4, pp. 954-97. Taubaté, 2016. 